Revised Manuscript for Water research

Date: 2017-01-25

\title{
Ferrous iron/peroxymonosulfate oxidation as a pretreatment for ceramic ultrafiltration membrane: Control of natural organic matter fouling and degradation of atrazine
}

Xiaoxiang Cheng ${ }^{a}$, Heng Liang ${ }^{a}$, , An Ding ${ }^{a}$, Xiaobin Tang ${ }^{a}$, Bin Liu ${ }^{a}$, Xuewu Zhu ${ }^{a}$, Zhendong Gan ${ }^{a}$, Daoji $\mathrm{Wu}^{b}$, Guibai $\mathrm{Li}^{a}$

${ }^{a}$ State Key Laboratory of Urban Water Resource and Environment (SKLUWRE),

Harbin Institute of Technology, 73 Huanghe Road, Nangang District, Harbin 150090, P.R. China

${ }^{b}$ School of Municipal and Environmental Engineering, Shandong Jianzhu University, 1000 Fengming Road, Licheng District, Jinan 250101, P.R. China

(E-mail addresses: cxx19890823@163.com (X. Cheng); hitliangheng@163.com (H. Liang);dinganhit@gmail.com (A. Ding); tang5462@163.com (X. Tang); ahxclb@163.com (B. Liu); zhuxuewu1314@163.com (X. Zhu); ganzhendong_hit@163.com (Z.Gan); wdj@sdjzu.edu.cn (D.Wu); hitsteven@gmail.com (G. Li))

*Corresponding author.

Tel.: +86 451 86283001; Fax: +86 45186283001 .

E-mail address: hitliangheng@163.com (Heng Liang). 
Ferrous iron/peroxymonosulfate (Fe(II)/PMS) oxidation was employed as a

3 pretreatment method for ultrafiltration process to control membrane fouling caused

4 by natural organic matter, including humic acid (HA), sodium alginate (SA), bovine

5 serum albumin (BSA), and their mixture (HA-SA-BSA). To evaluate the mechanism

6 of fouling mitigation, the effects of $\mathrm{Fe}(\mathrm{II}) / \mathrm{PMS}$ pretreatment on the characteristics of

7 feed water were examined. The degradation of atrazine (ATZ) was also investigated

8 and the species of generated radicals were preliminarily determined. Under the test

9 exposure $(15$ and $50 \mu \mathrm{M}), \mathrm{Fe}(\mathrm{II}) / \mathrm{PMS}$ pretreatment effectively mitigated membrane

10 fouling caused by HA, SA and HA-SA-BSA mixture, and the performance improved

11 with the increase of $\mathrm{Fe}(\mathrm{II})$ or PMS dose; whereas aggravated BSA fouling at lower

12 doses and fouling alleviation was observed only at a higher dose $(50 / 50 \mu \mathrm{M})$. The

13 fouling mitigation was mainly attributed to the effective reduction of organic

14 loadings by coagulation with in-situ formed Fe(III). Its performance was comparable

15 or even slightly higher than single coagulation with $\mathrm{Fe}(\mathrm{III})$, most likely due to the

16 oxidation by $\mathrm{Fe}(\mathrm{II}) / \mathrm{PMS}$ process. Fe(II)/PMS oxidation showed better performance

17 in reducing DOC and $\mathrm{UV}_{254}$, fluorescence intensities of fluorescent components and

18 UV-absorbing compounds than single coagulation. In addition, Fe(II)/PMS

19 pretreatment was efficient in ATZ degradation due to the generation of sulfate and

20 hydroxyl radicals, whereas coagulation was ineffective to remove it.

21 Key words: Ferrous iron/peroxymonosulfate (Fe(II)/PMS), ceramic ultrafiltration

22 (UF) membrane, natural organic matter (NOM), membrane fouling, atrazine (ATZ) 


\section{Introduction}

Ultrafiltration (UF) membranes are being increasingly used in water and waste water treatment due to their effective retention of microorganisms, suspended particles, colloids, and some macromolecules (Jermann et al., 2007; Peter-Varbanets et al., 2009). Compared with polymeric UF membranes, ceramic UF membranes are emerging and promising in the field of water treatment because of their inherent advantages, such as higher mechanical and chemical stability, longer lifespan and increasing cost competitiveness (Lee et al., 2013; Lee and Kim, 2014). However, membrane fouling which may lead to more energy consumption and reduced productivity is still a critical obstacle for the further widespread application of ceramic UF membranes (Cheng et al., 2017). It was generally considered that natural organic matter (NOM, mainly including humic-like substances, polysaccharides, proteins, and lipids) was still one of the most problematic membrane foulants (Guo et al., 2009; Yuan and Zydney, 2000). Among various NOM fractions, the high molecular weight (MW) biopolymers such as proteinaceous substances and polysaccharides were identified as the main NOM components for UF membrane fouling (Zhang et al., 2015a). Some typically possible mechanisms were regarded as contributors to membrane fouling, including the formation of loose cake layer and impermeable gel layer, pore blocking and pore narrowing due to adsorption of organic matter (Qu et al., 2012; Zhang et al., 2015b).

A common approach to mitigate membrane fouling caused by organic matter is 4 feed water pretreatment prior to membrane filtration, which can remove the organic 
45 foulants with high fouling tendency or transform them into smaller fragments with 46 low fouling potential (Gao et al., 2011; Huang et al., 2009). The widely used 47 pretreatment methods for membrane fouling control mainly include coagulation/flocculation (Yu et al., 2013), adsorption (Li et al., 2014), oxidation (Van Geluwe et al., 2011), and their combinations (Wang et al., 2016). Although the common pretreatment methods showed certain effect on membrane fouling control,

51 there are still problems occurring in the practical application. Zhang et al. (2015a) 52 observed that coagulation pretreatment using aluminium chlorohydrate $(\mathrm{ACH})$ 53 achieved a remarkable reduction in both total and irreversible fouling resistance, 54 whereas it was ineffective for removing algal toxin microcystin-LR. Shao et al. 55 (2016) reported that powdered activated carbon (PAC) and humic acid (HA) 56 exhibited a significant synergistic fouling effect by forming a fouling layer together on the membrane surface in PAC-UF hybrid process. Our previous study (Cheng et

58 al., 2016) indicated that pre-ozonation with low doses efficiently alleviated 59 membrane fouling caused by HA and sodium alginate (SA) by converting high-MW 60 molecules into smaller ones, which could pass through membrane pores and 61 deteriorate the permeate quality. To solve these problems, ferrous-activated peroxymonosulfate (PMS), which is 63 one of the sulfate radicals $\left(\mathrm{SO}_{4}{ }^{-}\right.$)-based advanced oxidation processes (AOPs), was 64 put forward as a pretreatment alternative for ceramic UF membrane in this study. It 65 was reported that (Antoniou et al., 2010) PMS has a lower energy of the lower unoccupied molecular orbital (LUMO), which means that PMS is more easily to be 
activated by accepting $\mathrm{e}^{-}$than the other two peroxides, hydrogen peroxide $\left(\mathrm{H}_{2} \mathrm{O}_{2}\right)$ and persulfate (PDS). Owing to high activity, relatively lower cost and environmentally friendly nature, Fe(II) has been selected as an ideal activator of PMS (Zou et al., 2013). Rastogi et al. (2009a) reported that Fe(II)/PMS system showed a relatively higher reactivity for the degradation of 4-chlorophenol (4-CP) compared to $\mathrm{Fe}(\mathrm{II}) / \mathrm{PDS}$ and $\mathrm{Fe}(\mathrm{II}) / \mathrm{H}_{2} \mathrm{O}_{2}$. In previous studies, $\mathrm{Fe}(\mathrm{II}) / \mathrm{PMS}$ process has been utilized to degrade organic compounds such as polychlorinated biphenyls (PCBs) (Rastogi et al., 2009b) and 2,4-dichlorophenol (2,4-DCP) (Anipsitakis and Dionysiou, 2004) in aqueous solutions. To achieve a higher activation efficiency, previous research on $\mathrm{Fe}(\mathrm{II}) / \mathrm{PMS}$ oxidation were mainly performed under acidic conditions to avoid the formation of ferric oxyhydroxides through hydrolysis ( $\mathrm{Ji}$ et al., 2015; Rastogi et al., 2009b). However, very little effort has been put on the study of in-situ formed Fe(III), which could be used as a coagulant in neutral conditions. Moreover, the cost of Fe(II) salts is considerably lower than Fe(III) salts. To this end, $\mathrm{Fe}(\mathrm{II}) / \mathrm{PMS}$ process can be regarded as a combination of oxidation by $\mathrm{SO}_{4}{ }^{-}$and coagulation by $\mathrm{Fe}(\mathrm{III})$, which might simultaneously mitigate membrane fouling and improve the permeate quality. Considering that ceramic membrane can withstand the severe oxidizing environment in the presence of residual oxidants and radicals, it is of particular interest to integrate Fe(II)/PMS oxidation with ceramic membranes. However, to the best of our knowledge, very limited work has been done in this field.

The objective of this study was to investigate the effect of feed water 
pretreatment by $\mathrm{Fe}(\mathrm{II}) / \mathrm{PMS}$ on mitigating membrane fouling caused by different NOM fractions, including HA, SA and bovine serum albumin (BSA), as well as their

91 mixture (HA-SA-BSA). The impact of Fe(II)/PMS pretreatment on membrane

92 fouling was evaluated by (1) flux decline and reversibility analysis, (2)

93 characterization of the organic matter by various methods, and (3) comparing with

94 single coagulation by Fe(III). Furthermore, the effect of Fe(II)/PMS and coagulation

95 on the removal of atrazine (ATZ) was investigated and the species of generated

96 radicals were preliminarily determined. The results were expected to illustrate the

97 feasibility of Fe(II)/PMS pretreatment on UF membrane fouling control and the

98 improvement of permeate quality.

99

100

101

102

103

104

105

106

107

108

109

110

\section{Materials and methods}

\subsection{Materials and reagents}

HA, SA, BSA, and ATZ were purchased from Sigma-Aldrich (USA). Potassium peroxymonosulfate $\left(2 \mathrm{KHSO}_{5} \cdot \mathrm{KHSO}_{4} \cdot \mathrm{K}_{2} \mathrm{SO}_{4}\right)$, tert-butyl alcohol (TBA) and methanol were supplied by Aladdin Chemicals (Shanghai, China). All other reagents were of reagent grade quality and purchased from Bench Chemicals (Tianjin, China). HA, SA and BSA were chosen for preparing the feed solutions to represent humic substances, polysaccharides and proteins in natural waters, respectively. HA stock solution (2.0 g/L) was prepared by dissolving $2.0 \mathrm{~g}$ of HA in $800 \mathrm{~mL} \mathrm{NaOH}(0.01 \mathrm{~mol} / \mathrm{L})$, followed by stirring for $24 \mathrm{~h}$ and adjusting $\mathrm{pH}$ to 7.0 , and then the solution was diluted to $1000 \mathrm{~mL}$ with ultrapure water. The SA and BSA stock solutions $(2.0 \mathrm{~g} / \mathrm{L})$ were prepared by dissolving $2.0 \mathrm{~g}$ of SA and BSA in 1000 
$111 \mathrm{~mL}$ ultrapure water, respectively, and then stirring for $12 \mathrm{~h}$. The stock solution of

112 ATZ $(100 \mu \mathrm{M})$ was prepared by dissolving ATZ in ultrapure water, and then stirring

113 for $72 \mathrm{~h}$. The stock solutions of $\mathrm{FeSO}_{4}$ and PMS were freshly prepared by dissolving

114 weighed amounts of $\mathrm{FeSO}_{4}$ and PMS in ultrapure water, and standardized by

115 inductively coupled plasma optical emission spectrometry (ICP-OES) and the

116 iodometric method (Ball et al., 1967), respectively. These stock solutions were

117 stored in dark place. The employed concentrations of HA, SA and BSA samples with

118 individual fractions were all $10.0 \mathrm{mg} / \mathrm{L}$, while the HA-SA-BSA mixture with the

119 concentration of 5.0-5.0-5.0 $\mathrm{mg} / \mathrm{L}$ was utilized to investigate the combined fouling

120 of different organic fractions. In the experiment of ATZ removal, the water sample

121 was prepared by spiking $1.0 \mu \mathrm{M}$ ATZ into a $10.0 \mathrm{mg} / \mathrm{L} \mathrm{HA}$ solution. All samples

122 employed in the experiment were prepared by diluting stock solutions with ultrapure

123 water $(18.2 \mathrm{M} \Omega \cdot \mathrm{cm})$ produced by a Milli-Q purification system (Millipore, USA),

124 and the $\mathrm{pH}$ values were adjusted to $7.0 \pm 0.1$ prior to the experiment.

$125 \quad 2.2$ Experimental setup

126 The pretreatment experiments were performed in $500 \mathrm{~mL}$ triangular flasks at 127 room temperature $\left(25 \pm 1^{\circ} \mathrm{C}\right)$. The reactions of $\mathrm{Fe}(\mathrm{II}) / \mathrm{PMS}$ oxidation were initiated

128 by adding certain doses of PMS into water samples containing $\mathrm{Fe}(\mathrm{II})$ at desirable

129 concentrations. By contrast, the desired Fe(III) doses were added into water samples

130 to start the reaction of coagulation. In this study, PMS doses of 15 or $50 \mu \mathrm{M}$, and

131 initial $\mathrm{Fe}(\mathrm{II})$ concentrations of 15 or $50 \mu \mathrm{M}$ were employed. The pretreatments were

132 conducted in batch mode with rapid mixing for $1 \mathrm{~min}$ at $200 \mathrm{r} / \mathrm{min}$, followed by slow 
133 mixing for $20 \mathrm{~min}$ at $50 \mathrm{r} / \mathrm{min}$. After that, the pretreated water samples (without

134 removal of the precipitate) were immediately used for membrane filtration.

135 Filtration tests were carried out using a flat sheet ceramic UF membrane with

136 molecular weight cut-off of $50 \mathrm{kDa}$. The characteristics and images of the employed

137 membrane are shown in Table S1 and Fig. S1. A schematic representation of the UF

138 filtration experimental setup is illustrated in Fig. S2. UF experiments were

139 conducted in a filtration cell with an effective volume of $120 \mathrm{~mL}$ in dead-end mode

140 at a constant transmembrane pressure (TMP) of $50 \mathrm{kPa}$, which was maintained

141 through a nitrogen gas bottle connected to the filtration cell. For each experiment, a

142 piece of ceramic flat sheet membrane was placed at the bottom of the cell with its

143 filtration layer towards the feed water. During filtration, the permeate flux was

144 monitored using an electronic balance (BSA3202S, Sartorius, Germany) and the

145 output data was periodically recorded via a data acquisition system. In this study,

146 hydraulic backwash was utilized for membrane cleaning. Backwash was performed

147 by applying a higher pressure (approximately $150 \mathrm{kPa}$ ) on the permeate side, forcing

148 the permeate water back through the membrane to the feed side. As a result, the cake

149 layer attached on membrane surface was lifted and detached from ceramic

150 membrane. Membrane fouling analysis was calculated through the UF membrane

151 filtration experiment, which are described in detail in Section 2.3.

\section{$152 \quad 2.3$ Fouling analysis}

153 The distribution of fouling resistance was calculated using the

154 resistance-in-series model (Lin et al., 2009), as shown in Eq. (1): 


$$
R_{t}=T M P /(\mu J)=R_{m}+R_{i r}+R_{r}
$$

156

157 blocking, intermediate blocking and cake filtration (Qu et al., 2014) were employed

where, $T M P$ is the transmembrane pressure $(\mathrm{Pa}) ; \mu$ is the dynamic viscosity $(\mathrm{Pa} \cdot \mathrm{s}) ; J$ is the permeate flux $(\mathrm{m} / \mathrm{s}) ; R_{t}, R_{m}, R_{i r}$ and $R_{r}$ are the total hydraulic fouling resistance, intrinsic membrane resistance, hydraulic irreversible fouling resistance and hydraulic reversible fouling resistance $\left(\mathrm{m}^{-1}\right)$, respectively.

$$
R_{m} \text { was calculated through the filtration of ultrapure water and the permeate }
$$

flux was recorded as $J_{0}$, as shown in Eq. (2):

$$
R_{m}=T M P /\left(\mu J_{0}\right)
$$

$R_{t}$ was calculated according to the final permeate flux $\left(J_{l}\right)$ after filtration of water samples, as shown in Eq. (3):

$$
R_{t}=T M P /\left(\mu J_{1}\right)
$$

After each hydraulic backwash, the average ultrapure water flux of cleaned membrane was recorded as $J_{2}$. Hence, $R_{r}$ and $R_{i r}$ were calculated according to Eqs. (4) and (5), respectively.

$$
R_{r}=T M P /\left(\mu J_{1}\right)-T M P /\left(\mu J_{2}\right)
$$

$$
R_{i r}=R_{t}-R_{m}-R_{r}=T M P /\left(\mu J_{2}\right)-T M P /\left(\mu J_{0}\right)
$$

In addition, four classic fouling models, including complete blocking, standard to better understand the fouling behavior of different NOM fractions.

\subsection{Analytical methods}

Dissolved organic carbon (DOC) was analyzed using a total organic carbon (TOC) analyzer (multi N/C 2100, Jena, Germany) after filtering the sample by 0.45 
$177 \mu \mathrm{m}$ membrane. Ultraviolet absorbance $\left(\mathrm{UV}_{254}\right)$ was measured using an $\mathrm{UV} / \mathrm{vis}$

178 spectrophotometer (T6, Puxi, China) in terms of UV absorbance at the wavelength

179 of $254 \mathrm{~nm}$. The fluorescence excitation-emission matrices (EEMs) of organic matter

180 were characterized by a fluorescence spectrophotometer (F7000, Hitachi, Japan)

181 with a $1 \mathrm{~cm}$ cuvette. EEMs were generated by scanning over excitation (Ex)

182 wavelengths of 200-450 $\mathrm{nm}$ at $5 \mathrm{~nm}$ increments and emission (Em) wavelengths of

$183250-550 \mathrm{~nm}$ at $1 \mathrm{~nm}$ increments. In order to remove most of the Raman scatter peaks

184 in fluorescence spectra, an EEM of ultrapure water was subtracted from each sample

185 EEM. In addition, the area under the Raman scatter peak $(E x=350 \mathrm{~nm}$ and

$186 E m=381-426 \mathrm{~nm}$ ) of an ultrapure water sample (run the same day) was employed for

187 Raman normalization and the obtained fluorescence intensities in this study were in

188 Raman units (R.U., $\mathrm{nm}^{-1}$ ) (Murphy et al., 2010). A high-performance size exclusion

189 chromatography with UV detection (HPSEC-UV) was utilized to measure the

190 apparent MW distributions. The measurement was performed using a

191 high-performance liquid chromatograph (HPLC) (Agilent 1200) coupled with a

192 TSK-gel G4000PW $\mathrm{XL}_{\mathrm{XL}}$ silica gel column $(7.8 \times 300 \mathrm{~mm}, 10 \mu \mathrm{m})(\mathrm{TOSOH}, \mathrm{Japan})$.

193 The mobile phase for HPSEC was phosphate buffer solution $(0.1 \mathrm{~mol} / \mathrm{L} \mathrm{NaCl}, 0.002$

$194 \mathrm{~mol} / \mathrm{L} \mathrm{K}_{2} \mathrm{HPO}_{4}$ and $0.002 \mathrm{~mol} / \mathrm{L} \mathrm{KH}_{2} \mathrm{PO}_{4}, \mathrm{pH}=6.85$ ), and the flow rate was

195 controlled at $0.3 \mathrm{~mL} / \mathrm{min}$. More details about the measurement can be found in our

196 previous paper (Cheng et al., 2016). Moreover, ATZ was also analyzed by the HPLC

197 coupled with a Spherisorb S5 ODS2 column $(4.6 \times 250 \mathrm{~mm}, 5 \mu \mathrm{m})$ (Waters, USA)

198 using UV detection at $225 \mathrm{~nm}$. The mobile phase was composed of ultrapure water 

temperature was set at $30^{\circ} \mathrm{C}$.

\section{Results}

\subsection{Effect of $\mathrm{Fe}(\mathrm{II}) / \mathrm{PMS}$ pretreatment on membrane fouling}

\subsubsection{HA fouling}

The effect of $\mathrm{Fe}(\mathrm{II}) / \mathrm{PMS}$ pretreatment on HA fouling of ceramic UF membrane was investigated and the results are shown in Fig. 1. As illustrated in Fig. 1(a), untreated HA resulted in significant flux decline, and the terminal specific fluxes were reduced to 0.55 and 0.47 during the first and second filtration cycle, respectively. Feed water pretreated by $\mathrm{Fe}(\mathrm{II}) / \mathrm{PMS}$ oxidation with the dose of $15 / 15$ $\mu \mathrm{M}$ obviously improved membrane flux. Increasing the initial concentration of PMS

211 greater flux improvement. The flux curve became almost horizontal after treatment

212 by $\mathrm{Fe}(\mathrm{II}) / \mathrm{PMS}$ with the molar ratio of $1: 1(50 / 50 \mu \mathrm{M})$, indicating that best flux

213 improvement was achieved at this dose level, which was comparable to coagulation

214 with $50 \mu \mathrm{M}$ Fe(III). Under different doses, Fe(II)/PMS pretreatment significantly 215 improved permeate flux with a promotion of terminal specific flux from 0.47 to $216 \quad 0.66-0.93$.

218 As shown in Fig. 1(b), untreated HA caused most severe reversible and

219 irreversible membrane fouling with the fouling resistance of 0.443 and $0.425 \times 10^{12}$ $220 \mathrm{~m}^{-1}$, respectively. When the sample was pretreated by $\mathrm{Fe}(\mathrm{II}) / \mathrm{PMS}$, both reversible 
221 and irreversible fouling significantly reduced by the rate of $23.5 \%-83.5 \%$ and $22268.9 \%-96.5 \%$, respectively. It was suggested that more irreversible fouling was 223 reduced compared with reversible fouling. The reversible fouling resistance of 224 pretreated HA by $50 / 50 \mu \mathrm{M}$ Fe(II)/PMS was slightly lower than that of the sample 225 pretreated by $50 \mu \mathrm{M} \mathrm{Fe}(\mathrm{III})$. In addition, the regression results using classic fouling 226 models are shown in Table 1 and Fig. S3. As for untreated HA, the correlation 227 coefficient $\left(R^{2}\right)$ values were $0.682,0.997,0.768$ and 0.842 for complete blocking, 228 standard blocking, intermediate blocking and cake filtration, respectively, indicating 229 that the main mechanism for flux decline caused by HA was standard blocking. 230 When HA was treated by Fe(II)/PMS prior to filtration, $R^{2}$ values for the models 231 significantly increased except for standard blocking, indicating the decreasing roles 232 played by standard blocking. As for HA, Fe(II)/PMS pretreatment exhibited an 233 excellent performance in improving membrane flux, reducing both reversible and 234 irreversible fouling, and decreasing the role of standard blocking.

$235 \quad 3.1 .2$ SA fouling

236 Fig. 2(a) illustrates that Fe(II)/PMS oxidation dramatically improved the 237 permeate flux in the filtration of SA. The performance improved with the increase of $238 \mathrm{Fe}(\mathrm{II}) / \mathrm{PMS}$ dose and the best performance was observed at the dose of $50 / 50 \mu \mathrm{M}$, by 239 which the specific flux increased from 0.24 and 0.20 to 0.66 and 0.63 at the end of 240 the first and second cycle, respectively. Fig. 2(b) shows that untreated SA induced 241 more severe reversible fouling compared with irreversible fouling. This result was 242 consistent with previous studies (Cheng et al., 2016; Li et al., 2014) which reported 
244 layer. This part of fouling could easily be removed by hydraulic backwash and the

245 flux was recovered immediately. It can also be seen that the reversible fouling 246 gradually decreased with the increase of Fe(II) and PMS doses, whereas the 247 irreversible fouling increased to varying degrees at relatively lower doses and began 248 to decrease until the maximum dose reached. In addition, compared with 249 pretreatment by $50 / 50 \mu \mathrm{M} \mathrm{Fe}(\mathrm{II}) / \mathrm{PMS}$, the same dose of $\mathrm{Fe}(\mathrm{III})$ showed similar 250 efficiency in reducing the total fouling resistance. The regression results (Table 1) 251 indicated that the fouling mechanism of untreated SA was mainly ascribed to the 252 combination of standard blocking $\left(R^{2}=0.999\right)$ and cake filtration $\left(R^{2}=0.998\right)$. After 253 treatment by $\mathrm{Fe}(\mathrm{II}) / \mathrm{PMS}$, the $R^{2}$ values for cake filtration decreased to 0.996 and 254 0.982, implying that the pretreatment decreased the role of cake filtration. These 255 results indicated that $\mathrm{Fe}(\mathrm{II}) / \mathrm{PMS}$ showed a significant effect for mitigating 256 membrane fouling by SA and decreasing the role of cake filtration, irrespective of 257 the increase of irreversible fouling resistance at lower Fe(II)/PMS doses.

\section{$259 \quad$ 3.1.3 BSA fouling}

260 As shown in Fig. 3(a), the membrane was severely fouled by untreated BSA 261 and the specific flux rapidly declined in the initial filtration stage. Instead of 262 improving membrane flux, Fe(II)/PMS pretreatment at lower doses caused more 263 serious flux decline. When the Fe(II)/PMS dose increased to $50 / 50 \mu \mathrm{M}$, the 264 permeate flux was improved with a promotion of terminal specific flux from 0.19 
265 and 0.13 to 0.38 and 0.28 during the first and second cycle, respectively. The 266 promotion effect was comparable to single coagulation with $50 \mu \mathrm{M} \mathrm{Fe}$ (III). It can 267 also be seen that the flux was difficult to be recovered through hydraulic backwash.

268 Fig. 3(b) shows that untreated BSA caused both severe reversible and irreversible 269 fouling. Although the total fouling resistance changed with the change of $270 \mathrm{Fe}(\mathrm{II}) / \mathrm{PMS}$ dose, the distribution of reversible and irreversible fouling changed little.

271 Table 1 shows that standard blocking played a major role in BSA fouling with the $R^{2}$ 272 value of $0.995 . \mathrm{Fe}(\mathrm{II}) / \mathrm{PMS}$ pretreatment with the dose of $15 / 15 \mu \mathrm{M}$ decreased the $R^{2}$ 273 values for complete blocking, intermediate blocking and cake filtration, whereas the 274 dose of $50 / 50 \mu \mathrm{M}$ significantly increased the values. The effect of $\mathrm{Fe}(\mathrm{II}) / \mathrm{PMS}$ 275 pretreatment on BSA fouling was closely associated with its dose. Specifically, 276 relatively higher doses of $\mathrm{Fe}(\mathrm{II}) / \mathrm{PMS}$ (under the tested exposure) apparently 277 alleviated membrane fouling, whereas fouling aggravated at lower doses.

279 3.1.4 HA-SA-BSA fouling

280 Since humic substances, polysaccharides and proteins are usually 281 simultaneously present in natural waters, the mixture of HA-SA-BSA was employed 282 to investigate the effect of Fe(II)/PMS pretreatment on the combined fouling. As 283 shown in Fig. 4(a), Fe(II)/PMS dramatically improved the flux and the terminal 284 specific flux increased from 0.15 to $0.40,0.45,0.55$ and 0.79 with the doses of $15 / 15$, $28515 / 50,50 / 15$ and 50/50 $\mu \mathrm{M}$, respectively. Furthermore, Fe(II)/PMS oxidation with 286 the dose of $50 / 50 \mu \mathrm{M}$ led to a higher flux improvement than coagulation with $50 \mu \mathrm{M}$ 
Fe(III) (0.64 cf. 0.58). As shown in Fig. 4(b), membrane fouling caused by untreated sample was dominated by reversible fouling, which could be eliminated through

289 hydraulic backwash. All fouling resistances, including the total, reversible and 290 irreversible fouling resistances gradually decreased with the increase of $\mathrm{Fe}(\mathrm{II}) / \mathrm{PMS}$

291 dose, indicating that Fe(II)/PMS was efficient for alleviating membrane fouling caused by the mixture of HA, SA and BSA. As shown in Table 1, the untreated 293 sample both fit the models of standard blocking $\left(R^{2}=0.999\right)$ and cake filtration 294 ( $\left.R^{2}=0.990\right)$. Fe(II)/PMS pretreatment decreased the $R^{2}$ values for cake filtration to 2950.857 and 0.962 , suggesting that the fouling mitigation was mainly ascribed to the 296 removal of cake layer on membrane surface.

Fig. 4

\subsection{Characterization of the feed water pretreated by Fe(II)/PMS}

DOC and $\mathrm{UV}_{254}$ were tested to characterize the total dissolved organic matter

301 and the organics containing unsaturated bonds or aromatic chromophores (primarily

302 humic substances), respectively (Leenheer and Croué, 2003). The variations of DOC 303 and $\mathrm{UV}_{254}$ for the UF feed water treated with $\mathrm{Fe}(\mathrm{II}) / \mathrm{PMS}$ and $\mathrm{Fe}(\mathrm{III})$ were examined, 304 and the results are illustrated in Fig. 5. In terms of HA, PMS alone (50 $\mu \mathrm{M})$ exerted 305 a minor influence on DOC removal. A higher DOC reduction was achieved for the 306 higher Fe(II) dose at the same dose of PMS. With the Fe(II) dose increased from 15 to $50 \mu \mathrm{M}$, the DOC removal rate increased from $26.8 \%$ to $56.8 \%$ and $40.8 \%$ to $93.0 \%$

308 under the PMS doses of 15 and $50 \mu \mathrm{M}$, respectively. In addition, Fe(II)/PMS showed 
309 a higher efficiency in DOC removal than Fe(III) at the same Fe dose (26.8\% cf. 20.0\%

310 and $93.0 \%$ cf. $86.6 \%$ ). It seemed that the in-situ formed Fe(III) was slightly more

311 effective than the dosed Fe(III) in DOC removal, most likely due to the oxidation by

312 Fe(II)/PMS process. Previous studies (Guan et al., 2009; Lee et al., 2009) also

313 reported similar findings in arsenic and phosphate removals. The DOC removals for

314 SA and the mixture presented similar rules as that of HA. As for BSA, only

315 treatment with $50 / 50 \mu \mathrm{M} \mathrm{Fe}(\mathrm{II}) / \mathrm{PMS}$ or $50 \mu \mathrm{M} \mathrm{Fe}(\mathrm{III})$ led to an obvious DOC

316 removal. As shown in Fig. 5(b), the removals of $\mathrm{UV}_{254}$ were in similar trends as that

317 of DOC. Under different Fe(II)/PMS doses, the $\mathrm{UV}_{254}$ levels were decreased from

3180.367 and $0.173 \mathrm{~cm}^{-1}$ to $0.014-0.177$ and $0.013-0.097 \mathrm{~cm}^{-1}$ for HA and the mixture,

319 respectively. These results suggested that Fe(II)/PMS pretreatment led to significant

320 removal of DOC and $\mathrm{UV}_{254}$ at proper doses, and the removal rates were slightly

321 higher than by single coagulation with the same dose of Fe(III).

\section{3.2.2 Fluorescence EEM spectra}

324 To investigate the performance of $\mathrm{Fe}(\mathrm{II}) / \mathrm{PMS}$ and $\mathrm{Fe}(\mathrm{III})$ pretreatments for 325 fluorescent components removal, the fluorescence EEM spectra of HA, BSA and the 326 mixture were obtained (Fig. S4). Since polysaccharides cannot be detected using 327 fluorescence spectroscopy (Shao et al., 2014), SA was not investigated here. As 328 shown in Fig. S4, there are three significant peaks in the spectra, including 329 HA/Mixture1 (Ex/Em: 260/430 nm, humic-like substances), BSA1/Mixture2 330 (Ex/Em: 275/340 nm, tryptophan-like protein substances) and BSA2/Mixture3 
331 (Ex/Em: 225/340 nm, tryptophan-like protein substances) (Chen et al., 2003). The 332 normalized fluorescence intensities of each peak for the UF feed water treated with

$333 \mathrm{Fe}(\mathrm{II}) / \mathrm{PMS}$ and $\mathrm{Fe}(\mathrm{III})$ are illustrated in Fig. 6. In terms of humic-like substances, 334 the fluorescence intensities of HA reduced from 0.57 to $0.05,0.02,0.25$ and 0.12 , 335 while that of Mixture1 reduced from 0.39 to $0.06,0.02,0.16$ and 0.07 after treated 336 with $15 / 15 \mu \mathrm{M}$ Fe(II)/PMS, 50/50 $\mu \mathrm{M}$ Fe(II)/PMS, $15 \mu \mathrm{M}$ Fe(III) and $50 \mu \mathrm{M}$ Fe(III), 337 respectively. At the same dose of $\mathrm{Fe}, \mathrm{Fe}(\mathrm{II}) / \mathrm{PMS}$ oxidation showed significantly 338 better performance in reducing the fluorescence intensities of humic-like and 339 tryptophan-like protein substances than single coagulation with $\mathrm{Fe}(\mathrm{III})$. The results 340 suggested the formation of some oxidative radicals during the $\mathrm{Fe}(\mathrm{II}) / \mathrm{PMS}$ process, 341 which reduced fluorescence intensities by changing the fluorescence characteristics 342 of each NOM fraction (discussed in Section 4).

$344 \quad 3.2 .3$ Size exclusion chromatography

345 The apparent molecular weight distributions of UV-absorbing compounds in 346 the UF feed water treated with $\mathrm{Fe}(\mathrm{II}) / \mathrm{PMS}$ and $\mathrm{Fe}(\mathrm{III})$ were determined by 347 HPSEC-UV (Fig. 7). It should be noted that the UV detector only detects limited 348 components (mostly $\pi$ bonded molecules) of organic matter, and some molecular 349 size fractions can only be measured using a DOC detector (Her et al., 2002a; Her et 350 al., 2002b). Therefore, the HPSEC-UV method was used only for limited qualitative 351 analysis in this study. The sample of untreated HA contained humic substances, 352 building blocks (breakdown products of humic substances (Henderson et al., 2011)) 
353 and low MW organic matter. Besides, the untreated mixture also included 354 biopolymers (high MW substances), which was caused by the addition of protein 355 and polysaccharide. After treatment with Fe(II)/PMS or coagulation, the peaks of 356 humic substances, building blocks and low MW organic matter in both HA and the 357 mixture were significantly reduced, whereas the peak of biopolymers in the mixture 358 disappeared. The results indicated that both Fe(II)/PMS and coagulation were 359 efficient for removing UV-absorbing compounds over a wide MW range. As for $360 \mathrm{Fe}(\mathrm{II}) / \mathrm{PMS}$ treatment, the overall UV absorbance gradually decreased with the 361 increase of $\mathrm{Fe}(\mathrm{II}) / \mathrm{PMS}$ dose (under the exposure of 15 and $50 \mu \mathrm{M}$ ). Coagulation 362 with $\mathrm{Fe}(\mathrm{III})$ exhibited a similar trend as $\mathrm{Fe}(\mathrm{II}) / \mathrm{PMS}$ oxidation. For both HA and the

363 mixture, the overall UV response of Fe(III) coagulated sample was higher than that 364 of $\mathrm{Fe}(\mathrm{II}) / \mathrm{PMS}$ treated feed water (at the same dose of $\mathrm{Fe}$ ), indicating that the high 365 UV-absorbing compounds in HA and the mixture were more susceptible to the 366 treatment of $\mathrm{Fe}(\mathrm{II}) / \mathrm{PMS}$ than coagulation by $\mathrm{Fe}(\mathrm{III})$.

Fig. 7

\subsection{Effect of $\mathrm{Fe}(\mathrm{II}) / \mathrm{PMS}$ pretreatment on ATZ degradation}

369 Due to the high effectiveness for the control of grassy weeds, broad leaf and 370 algae, ATZ (2-chloro-4-ethylamino-6-isopropylamino-s-triazine) has been one of the 371 most widely used herbicides around the world (Graymore et al., 2001). However, 372 ATZ is toxic and harmful to humans and animals, which exhibits a high potential to 373 contaminate the source of drinking water (Nelkenbaum et al., 2009). To this end, 374 ATZ was employed to investigate the oxidation characteristic of $\mathrm{Fe}(\mathrm{II}) / \mathrm{PMS}$ 
375 pretreatment and justify its applicability for water quality control during herbicides 376 pollution.

377 The concentrations of ATZ in the feed and permeate were measured, and the 378 results are shown in Fig. 8(a). After coagulation with $\mathrm{Fe}(\mathrm{III})(15$ and $50 \mu \mathrm{M})$, the 379 concentrations of ATZ remained unchanged, indicating that coagulation was 380 ineffective for ATZ removal. The result was consistent with previous studies

381 (Alizadeh Tabatabai et al., 2014; Zhang et al., 2015a), which reported that 382 coagulation exerted minor effect on the removal of small organic molecules. PMS 383 alone $(50 \mu \mathrm{M})$ exhibited a poor efficiency with the removal rate of less than $9 \%$. By 384 contrast, $\mathrm{Fe}(\mathrm{II}) / \mathrm{PMS}$ oxidation with a dose of $15 / 15 \mu \mathrm{M}$ significantly reduced ATZ 385 concentration with a removal efficiency of $72.2 \%$, and increasing the dose of PMS 386 to $50 \mu \mathrm{M}$ led to a higher efficiency (85.6\%). However, the removal efficiency 387 significantly decreased to $35.9 \%$ when the $\mathrm{Fe}(\mathrm{II})$ dose increased to $50 \mu \mathrm{M}$. Similar 388 results were reported by the study of Rastogi et al. (2009b), which showed that 389 excessive $\mathrm{Fe}(\mathrm{II})$ could be detrimental for the degradation efficiency of $\mathrm{Fe}(\mathrm{II}) / \mathrm{PMS}$ 390 process. This was caused by the competition of generated radicals between $\mathrm{Fe}(\mathrm{II})$ 391 and ATZ, which reduced the concentration of radicals reacted with ATZ. When $392 \mathrm{Fe}(\mathrm{II}) / \mathrm{PMS}$ dose increased to $50 / 50 \mu \mathrm{M}$, the removal rate reached up to $98.2 \%$ and 393 the residual ATZ was almost undetectable. The permeate ATZ concentration of 394 ceramic UF membrane was slightly lower than that in the feed (the removal rate 395 lower than 10\%). Since the molecular size of ATZ (MW=215.68) was much smaller 396 than the pore size of UF membrane, and it was difficult to be rejected by the 
membrane through size exclusion, therefore the rejection was likely due to the mechanisms of adsorption or electrostatic repulsion ( $\mathrm{Li}$ et al., 2014). Considering the low retention rate by single membrane filtration, $\mathrm{Fe}(\mathrm{II}) / \mathrm{PMS}$ pretreatment played an important role in the removal of ATZ.

\section{Fig. 8}

In addition, TBA and methanol were employed as radical scavengers to preliminarily identify the species of generated radicals in the $\mathrm{Fe}(\mathrm{II}) / \mathrm{PMS}$ process. TBA was a strong hydroxyl radical $\left({ }^{\circ} \mathrm{OH}\right)$ scavenger due to the high rate constant $\left(k \cdot \mathrm{OH}, \mathrm{TBA}=3.8-7.6 \times 10^{8} \mathrm{M}^{-1} \mathrm{~s}^{-1}\right)$, whereas it was less sensitive to $\mathrm{SO}_{4}{ }^{\cdot-}\left(k_{\mathrm{SO}}{ }^{\cdot-},{ }^{-} \mathrm{TBA}=\right.$ 4.0-9.1 $\times 10^{5} \mathrm{M}^{-1} \mathrm{~s}^{-1}$ ) (Cong et al., 2015). By contrast, methanol reacts with both ${ }^{\circ} \mathrm{OH}$ and $\mathrm{SO}_{4}{ }^{\circ}$. Under the $\mathrm{Fe}(\mathrm{II}) / \mathrm{PMS}$ dose of $50 / 50 \mu \mathrm{M}$, the ATZ removal rate decreased from $98.2 \%$ to $43.7 \%$ and $32.6 \%$ in the presence of $1 \mathrm{mM}$ TBA and $1 \mathrm{mM}$ methanol, respectively (Fig. 8(b)). When the addition of TBA and methanol both increased to $2 \mathrm{mM}$, the corresponding removal rates further reduced to $36.3 \%$ and $26.6 \%$, respectively. Similar result was observed at the Fe(II)/PMS dose of 15/15 $\mu \mathrm{M}$, suggesting that TBA inhibited the effect of ${ }^{\circ} \mathrm{OH}$ and methanol inhibited both the effects of ${ }^{\circ} \mathrm{OH}$ and $\mathrm{SO}_{4}{ }^{-}$. This result indicates the presence of both ${ }^{\circ} \mathrm{OH}$ and $\mathrm{SO}_{4}{ }^{-}$in the process of $\mathrm{Fe}(\mathrm{II}) / \mathrm{PMS}$ oxidation.

Besides ATZ, some other trace organics, including sulfamethoxazole, sulfamethazine, sulfamethoxydiazine and $p$-chloronitrobenzene were also investigated. The details about the experiment and the results are shown in Text S1 and Fig. S5, respectively. It can be seen that $\mathrm{Fe}(\mathrm{II}) / \mathrm{PMS}$ pretreatment also 
419 significantly improved the removal efficiencies of these organics, whereas 420 conventional $\mathrm{Fe}$ coagulation was ineffective for removing them. The results

421 indicated that the removal performance of Fe(II)/PMS was not restricted to ATZ.

422 The detailed reaction mechanism will be discussed in Section 4.

\section{4. Discussion}

The above results demonstrated that Fe(II)/PMS oxidation was a promising pretreatment method to simultaneously control membrane fouling and ensure 426 product water quality for ceramic UF membrane (under appropriate exposure). The 427 principal reactions in the Fe(II)/PMS process and second-order rate constants are 428 summarized in Table 2. Since the flux improvement was comparable or slightly 429 higher than coagulation with $\mathrm{Fe}(\mathrm{III})$, the in-situ formed $\mathrm{Fe}(\mathrm{III})$ (reaction 1) most 430 likely played a major role in fouling mitigation. As shown in Table 3, the PMS 431 concentration decreased rapidly within $1 \mathrm{~min}$ and remained nearly constant in the 432 last $20 \mathrm{~min}$, indicating that Fe (III) was formed immediately after the addition of 433 PMS, irrespective of the Fe(II)/PMS dose. This could be interpreted by the fast 434 reactions between $\mathrm{Fe}(\mathrm{II})$ and PMS. The molar ratio of $\mathrm{Fe}(\mathrm{II})$ and PMS played an 435 important role in PMS consumption and the formation of $\mathrm{Fe}(\mathrm{III})$. At the same dose 436 of $\mathrm{Fe}(\mathrm{II})(50 \mu \mathrm{M})$, the residual Fe concentration could be reduced from 27.2 to 4.8 $437 \mu \mathrm{M}$ with the PMS dose increased from 15 to $50 \mu \mathrm{M}$, indicating that PMS was a 438 limiting reagent to produce Fe (III) (Table 3). Excessive Fe(II) or PMS caused the 439 waste of reagents and the optimal molar ratio of Fe(II)/PMS was 1:1.

440 The in-situ formed Fe(III) could be functioned as a coagulant, which was able 
441 to form larger flocs after reacting with water through charge neutralization and 442 sweep-coagulation (Gao et al., 2011). A proper dose of Fe(II)/PMS could reduce the 443 organic loading of feed by forming settable flocs with a larger size, which was much 444 bigger than the pore size of ceramic UF membrane and rejected by the membrane. 445 Accordingly, membrane fouling caused by different NOM fractions was 446 significantly reduced under optimal doses. However, although SA fouling was 447 significantly mitigated, an increase of irreversible fouling resistance was still 448 observed under lower Fe(II)/PMS doses. This was caused by the formation of some 449 micro-flocs, which increased the occurrence of pore blocking/constriction. Due to 450 the narrow MW distribution of BSA, lower doses of Fe(II)/PMS led to the formation 451 of more micro-flocs, which fully blocked membrane pores to cause significant flux 452 reduction. Ma et al. (2014) reported similar results when studying the effect of low 453 dose of coagulant on the performance of UF membrane. As for HA-SA-BSA 454 mixture, since proteins (BSA) could be encapsulated by humic substances (HA) 455 because of the electrostatic attraction (Tan et al., 2008), lower doses of Fe(II)/PMS 456 still improved the membrane flux.

457 Coagulation with in-situ formed Fe(III) efficiently reduced the levels of DOC 458 and $\mathrm{UV}_{254}$ of feed water and the organic loadings for ceramic UF membrane, which 459 were responsible for membrane fouling control. Activation of PMS by Fe(II) led to 460 the formation of $\mathrm{SO}_{4}{ }^{--}$(reaction 1), which was transformed into ${ }^{\circ} \mathrm{OH}$ under alkaline 461 conditions (reaction 2), and ${ }^{\circ} \mathrm{OH}$ also reacted with sulfate groups and oxidized them 462 to $\mathrm{SO}_{4}{ }^{--}$at strong acidic conditions (reaction 3). Therefore, both $\mathrm{SO}_{4}{ }^{-}$and ${ }^{\circ} \mathrm{OH}$ were 
463

presented in the $\mathrm{Fe}(\mathrm{II}) / \mathrm{PMS}$ process under the current experimental conditions. Because of the oxidation characteristics, $\mathrm{SO}_{4}{ }^{--}$and ${ }^{\circ} \mathrm{OH}$ showed better performance in reducing fluorescence intensities of fluorescent components and UV-absorbing compounds than coagulation with $\mathrm{Fe}(\mathrm{III})$. In addition, $\mathrm{SO}_{4}{ }^{-}$and ${ }^{\circ} \mathrm{OH}$ oxidation also contributed to the removal of DOC and $\mathrm{UV}_{254}$ levels of the feed water, therefore $\mathrm{Fe}(\mathrm{II}) / \mathrm{PMS}$ pretreatment was slightly more effective than single coagulation in membrane fouling mitigation.

Due to the high reaction rate between the generated radicals and ATZ (reactions 6 and 7), Fe(II)/PMS oxidation was also very effective in ATZ degradation. The reactions of $\mathrm{SO}_{4}{ }^{-}$and ${ }^{\circ} \mathrm{OH}$ with $\mathrm{ATZ}$ led to dealkylation and produced some intermediate products, including desethyl-atrazine, desisopropyl-atrazine, acetaldehyde and acetone (Lutze et al., 2015). However, excessive Fe(II) was detrimental for the degradation efficiency of ATZ because it consumed the generated $\mathrm{SO}_{4}{ }^{-}$and ${ }^{\circ} \mathrm{OH}$ (reactions 4 and 5). As shown in reactions 8 and $9,{ }^{\circ} \mathrm{OH}$ and $\mathrm{SO}_{4}{ }^{\circ-}$

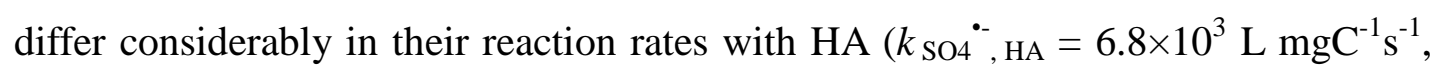
$\left.k \cdot \mathrm{OH}, \mathrm{HA}=1.4 \times 10^{4} \mathrm{~L} \mathrm{mgC}^{-1} \mathrm{~s}^{-1}\right)$. Since ${ }^{\bullet} \mathrm{OH}$ reacts more fast with $\mathrm{HA}$ than $\mathrm{SO}_{4}{ }^{-}$, ATZ was degraded more efficiently by $\mathrm{SO}_{4}{ }^{-}$than by ${ }^{\circ} \mathrm{OH}$ in the presence of HA. Due to the higher selectivity of $\mathrm{SO}_{4}{ }^{-}$than ${ }^{\circ} \mathrm{OH}, \mathrm{SO}_{4}{ }^{-}-$-based AOPs have advantages over common AOPs ( ${ }^{\circ} \mathrm{OH}-$ based) for ATZ degradation in the presence of organic matter. In the $\mathrm{Fe}(\mathrm{II}) / \mathrm{PMS}$ process, $\mathrm{SO}_{4}{ }^{--}$was favorable for destruction of reactive organic contaminants, while ${ }^{\circ} \mathrm{OH}$ contributed to the degradation of $\mathrm{SO}_{4}{ }^{-}$-refractory organics, this complementarity led to an enhanced efficiency for contaminants degradation. In 
terms of coagulation, it was very effective to control membrane fouling caused by high MW organic matter and maintain the permeate flux, whereas ineffective for the removal of micropollutants (e.g. ATZ).

Overall, this study demonstrated that $\mathrm{Fe}(\mathrm{II}) / \mathrm{PMS}$ oxidation was an effective pretreatment for UF process, which simultaneously mitigated membrane fouling by different NOM fractions and controlled permeate water quality during ATZ pollution. However, it should be noted that the results obtained were based on surrogate organic foulants, which might have some discrepancies with real water samples ( $\mathrm{Li}$ et al., 2014). Moreover, although ceramic membrane is promising for membrane water treatment, polymeric membrane is still the mainstream. To this end, Songhua River water and polyethersulfone membrane were employed to verify the effectiveness of $\mathrm{Fe}(\mathrm{II}) / \mathrm{PMS}$ pretreatment. Fig. S6 shows that although the efficiency of $\mathrm{Fe}(\mathrm{II}) / \mathrm{PMS}$ pretreatment varied with the source of feed water to some extent, it was still effective for mitigating membrane fouling by real water samples. Its effectiveness for polymeric membrane was also verified (Fig. S6), indicating that the value of the pretreatment was not only restricted to ceramic membrane. From the standpoint of full-scale applications, $\mathrm{Fe}(\mathrm{II}) / \mathrm{PMS}$ oxidation is generally considered to be more expensive than traditional coagulation process due to the relatively higher cost of PMS, even though the cost of Fe(II) is lower than Fe(III). In addition, this study was conducted in a batch system, and the obtained results might be inconsistent with continuous operation since the accumulation of organic foulants on the membrane was a long-term process. Therefore, more detailed cost analyses and 
continuous operation should be further conducted for its full-scale applications.

508

509

\section{Conclusions}

In this study, the effects of feed water pretreatment by Fe(II)/PMS oxidation on UF membrane fouling control and the characteristics of different NOM fractions were investigated. The effect of Fe(II)/PMS pretreatment for ATZ degradation was also studied to exam its oxidation characteristic. The following conclusions can be drawn:

(1) $\mathrm{Fe}(\mathrm{II}) / \mathrm{PMS}$ pretreatment significantly mitigated membrane fouling caused by HA, SA and HA-SA-BSA mixture, and the performance improved with the increase of $\mathrm{Fe}(\mathrm{II})$ or PMS dose (under the exposure of 15 and $50 \mu \mathrm{M}$ ). Lower doses of $\mathrm{Fe}(\mathrm{II}) / \mathrm{PMS}$ aggravated membrane fouling caused by BSA, and fouling mitigation was observed only at a higher dose $(50 / 50 \mu \mathrm{M})$. The fouling control performance was comparable or even slightly higher than single coagulation with the same dose of $\mathrm{Fe}(\mathrm{III})$, most likely due to the oxidation by $\mathrm{Fe}(\mathrm{II}) / \mathrm{PMS}$ process.

(2) In the process of $\mathrm{Fe}(\mathrm{II}) / \mathrm{PMS}$, in-situ formed $\mathrm{Fe}(\mathrm{III})$ played an important role in the reduction of DOC and $\mathrm{UV}_{254}$ for different $\mathrm{NOM}$ fractions, which were responsible for membrane fouling control. Compared with coagulation by $\mathrm{Fe}(\mathrm{III})$, $\mathrm{Fe}(\mathrm{II}) / \mathrm{PMS}$ showed better performance in reducing DOC and $\mathrm{UV}_{254}$, fluorescence intensities of fluorescent components and UV-absorbing compounds.

(3) $\mathrm{Fe}(\mathrm{II}) / \mathrm{PMS}$ was effective in the degradation of ATZ $(98.2 \%$ at $50 / 50 \mu \mathrm{M})$ due to the presence of both ${ }^{\circ} \mathrm{OH}$ and $\mathrm{SO}_{4}{ }^{-}$, whereas coagulation exerted minor influence on removing it. The retention rate of ATZ by single membrane filtration was lower than $10 \%$, and $\mathrm{Fe}(\mathrm{II}) / \mathrm{PMS}$ pretreatment made major contributions to ATZ 
removal.

(4) PMS was a limiting reagent to produce Fe (III) and radicals from Fe (II) oxidation. Excessive Fe(II) or PMS caused the waste of reagents and excessive Fe(II) was also detrimental for ATZ degradation. The molar ratio of 1:1 for Fe(II) and PMS was optimal for both membrane fouling control and ATZ removal.

\section{Acknowledgements}

This research was jointly supported by the National Natural Science Foundation of China (51378140), the National Science Foundation for the Outstanding Youngster Fund (51522804), Program for New Century Excellent Talents in University (NCET-13-0169), State Key Laboratory of Urban Water Resource and Environment (2016DX01) and Fundamental Research Funds for the

\section{Central Universities.}

\section{References}

Alizadeh Tabatabai, S.A., Schippers, J.C., Kennedy, M.D., 2014. Effect of coagulation on fouling potential and removal of algal organic matter in ultrafiltration pretreatment to seawater reverse osmosis. Water Res. 59, 283-294.

Anipsitakis, G.P., Dionysiou, D.D., 2004. Radical generation by the interaction of transition metals with common oxidants. Environ. Sci. Technol. 38(13), 3705-3712.

Antoniou, M.G., de la Cruz, A.A., Dionysiou, D.D., 2010. Degradation of microcystin-LR using sulfate radicals generated through photolysis, thermolysis and $\mathrm{e}^{-}$transfer mechanisms. Appl. Catal. B 96(3-4), 290-298. 

excitation-emission matrix regional integration to quantify spectra for dissolved organic matter. Environ. Sci. Technol. 37(24), 5701-5710. matter (NOM) fractions: Membrane fouling mitigation, prediction and mechanism. J. Membr. Sci. 505, 15-25.

Eng. J. 308, 1010-1020. ozonation degradation of para-chlorobenzoic acid by peroxymonosulfate in aqueous

569 Membrane fouling control in ultrafiltration technology for drinking water production:

570 A review. Desalination 272(1-3), 1-8. 
574 effect of calcium ions on $\mathrm{As}(\mathrm{III})$ removal in the $\mathrm{KMnO}_{4}-\mathrm{Fe}(\mathrm{II})$ process. Water Res. 43(20), 5119-5128. detection. Environ. Sci. Technol. 36(15), 3393-3399.

591 Membranes in Water Treatment: A Review. Environ. Sci. Technol. 43(9), 3011-3019.

592 Jermann, D., Pronk, W., Meylan, S., Boller, M., 2007. Interplay of different 593 NOM fouling mechanisms during ultrafiltration for drinking water production. 594 Water Res. 41(8), 1713-1722. 
of ciprofloxacin and sulfamethoxazole by ferrous-activated persulfate: implications

597 for remediation of groundwater contaminated by antibiotics. Sci. Total Environ. 472, $598 \quad 800-808$.

599 Ji, Y., Dong, C., Kong, D., Lu, J., 2015. New insights into atrazine degradation 600 by cobalt catalyzed peroxymonosulfate oxidation: kinetics, reaction products and 601 transformation mechanisms. J. Hazard. Mater. 285, 491-500. degradation of atrazine in aqueous solution by $\mathrm{UV} / \mathrm{H}_{2} \mathrm{O}_{2} / \mathrm{Fe}^{2+}, \mathrm{UV} / \mathrm{S}_{2} \mathrm{O}_{8}{ }^{2-} / \mathrm{Fe}^{2+}$ and

$604 \mathrm{UV} / \mathrm{HSO}_{5}{ }^{-} / \mathrm{Fe}^{2+}$ processes: A comparative study. Chem. Eng. J. 218, 376-383. fouling characteristics of ceramic and polymeric microfiltration membranes using ceramic versus polymeric ultrafiltration membranes. Water Res. 48, 43-51.

614 Leenheer, J.A., Croué, J.-P., 2003. Peer Reviewed: Characterizing Aquatic 615 Dissolved Organic Matter. Environ. Sci. Technol. 37(1), 18A-26A.

616 Li, K., Liang, H., Qu, F., Shao, S., Yu, H., Han, Z.-s., Du, X., Li, G., 2014. 
617 Control of natural organic matter fouling of ultrafiltration membrane by adsorption 618 pretreatment: Comparison of mesoporous adsorbent resin and powdered activated 619 carbon. J. Membr. Sci. 471, 94-102.

620 Lin, C.F., Yu-Chen Lin, A., Sri Chandana, P., Tsai, C.Y., 2009. Effects of mass 621 retention of dissolved organic matter and membrane pore size on membrane fouling 622 and flux decline. Water Res. 43(2), 389-394.

623 Lutze, H.V., Bircher, S., Rapp, I., Kerlin, N., Bakkour, R., Geisler, M., von 624 Sonntag, C., Schmidt, T.C., 2015. Degradation of chlorotriazine pesticides by sulfate 625 radicals and the influence of organic matter. Environ. Sci. Technol. 49(3), $626 \quad 1673-1680$.

627 Ma, B., Yu, W., Liu, H., Qu, J., 2014. Effect of low dosage of coagulant on the 628 ultrafiltration membrane performance in feedwater treatment. Water Res. 51, $629 \quad 277-283$.

630 Murphy, K.R., Butler, K.D., Spencer, R.G., Stedmon, C.A., Boehme, J.R., 631 Aiken, G.R., 2010. Measurement of dissolved organic matter fluorescence in aquatic 632 environments: an interlaboratory comparison. Environ. Sci. Technol. 44(24), $6339405-9412$.

634 Nelkenbaum, E., Dror, I., Berkowitz, B., 2009. Reductive dechlorination of 635 atrazine catalyzed by metalloporphyrins. Chemosphere 75(1), 48-55.

636 Peter-Varbanets, M., Zurbrugg, C., Swartz, C., Pronk, W., 2009. Decentralized 637 systems for potable water and the potential of membrane technology. Water Res. 638 43(2), 245-265. 
640 membrane fouling by extracellular organic matters (EOM) of Microcystis

641 aeruginosa in stationary phase: influences of interfacial characteristics of foulants

642 and fouling mechanisms. Water Res. 46(5), 1490-1500.

643 Qu, F., Liang, H., Zhou, J., Nan, J., Shao, S., Zhang, J., Li, G., 2014.

644 Ultrafiltration membrane fouling caused by extracellular organic matter (EOM) from

645 Microcystis aeruginosa: Effects of membrane pore size and surface hydrophobicity.

646 J. Membr. Sci. 449, 58-66.

Rastogi, A., Al-Abed, S.R., Dionysiou, D.D., 2009a. Effect of inorganic,

648 synthetic and naturally occurring chelating agents on $\mathrm{Fe}(\mathrm{II})$ mediated advanced

649 oxidation of chlorophenols. Water Res. 43(3), 684-694.

650 Rastogi, A., Al-Abed, S.R., Dionysiou, D.D., 2009b. Sulfate radical-based

651 ferrous-peroxymonosulfate oxidative system for PCBs degradation in aqueous and

652 sediment systems. Appl. Catal. B 85(3-4), 171-179.

653 Shao, S., Liang, H., Qu, F., Yu, H., Li, K., Li, G., 2014. Fluorescent natural

654 organic matter fractions responsible for ultrafiltration membrane fouling:

655 Identification by adsorption pretreatment coupled with parallel factor analysis of

656 excitation-emission matrices. J. Membr. Sci. 464, 33-42.

657 Shao, S., Liang, H., Qu, F., Li, K., Chang, H., Yu, H., Li, G., 2016. Combined

658 influence by humic acid (HA) and powdered activated carbon (PAC) particles on

659 ultrafiltration membrane fouling. J. Membr. Sci. 500, 99-105.

660 Tan, W.F., Koopal, L.K., Norde, W., 2008. Interaction between humic acid and 
661 lysozyme, studied by dynamic light scattering and isothermal titration calorimetry.

662 Environ. Sci. Technol. 43(3), 591-596.

663 Van Geluwe, S., Braeken, L., Van der Bruggen, B., 2011. Ozone oxidation for 664 the alleviation of membrane fouling by natural organic matter: A review. Water Res. 665 45(12), 3551-3570.

666 Wang, H., Qu, F., Ding, A., Liang, H., Jia, R., Li, K., Bai, L., Chang, H., Li, G., 667 2016. Combined effects of PAC adsorption and in situ chlorination on membrane 668 fouling in a pilot-scale coagulation and ultrafiltration process. Chem. Eng. J. 283, $669 \quad 1374-1383$.

671 and hydroxyl radical by reaction of ozone with peroxymonosulfate: a novel 672 advanced oxidation process. Environ. Sci. Technol. 49(12), 7330-7339.

673 Yu, W.-z., Liu, H.-j., Xu, L., Qu, J.-h., Graham, N., 2013. The pre-treatment of 674 submerged ultrafiltration membrane by coagulation-Effect of polyacrylamide as a 675 coagulant aid. J. Membr. Sci. 446, 50-58.

676 Yuan, W., Zydney, A.L., 2000. Humic acid fouling during ultrafiltration. 677 Environ. Sci. Technol. 34(23), 5043-5050.

678 Zhang, X., Fan, L., Roddick, F.A., 2015a. Effect of feedwater pre-treatment 679 using $\mathrm{UV} / \mathrm{H}_{2} \mathrm{O}_{2}$ for mitigating the fouling of a ceramic MF membrane caused by 680 soluble algal organic matter. J. Membr. Sci. 493, 683-689.

681 Zhang, Z., Wang, Y., Leslie, G.L., Waite, T.D., 2015b. Effect of ferric and 682 ferrous iron addition on phosphorus removal and fouling in submerged membrane 
683 bioreactors. Water Res. 69, 210-222.

684 Zou, J., Ma, J., Chen, L., Li, X., Guan, Y., Xie, P., Pan, C., 2013. Rapid 685 acceleration of ferrous iron/peroxymonosulfate oxidation of organic pollutants by 686 promoting $\mathrm{Fe}(\mathrm{III}) / \mathrm{Fe}(\mathrm{II})$ cycle with hydroxylamine. Environ. Sci. Technol. 47(20), $687 \quad 11685-11691$. 
689 Table 1 Correlation coefficient $\left(R^{2}\right)$ values of regression analyses for membrane 690 fouling by different water samples.

\begin{tabular}{|c|c|c|c|c|c|}
\hline $\begin{array}{l}\mathrm{NOM} \\
\text { fraction }\end{array}$ & $\begin{array}{l}\text { Feed } \\
\text { Fe(II)/PMS } \\
\text { dose }(\mu \mathrm{M})\end{array}$ & $\begin{array}{l}\text { Complete } \\
\text { blocking }\end{array}$ & $\begin{array}{l}\text { Standard } \\
\text { blocking }\end{array}$ & $\begin{array}{l}\text { Intermediate } \\
\text { blocking }\end{array}$ & $\begin{array}{l}\text { Cake } \\
\text { filtration }\end{array}$ \\
\hline \multirow{3}{*}{ HA } & $0 / 0$ & 0.682 & 0.997 & 0.768 & 0.842 \\
\hline & $15 / 15$ & 0.857 & 0.999 & 0.895 & 0.927 \\
\hline & $50 / 50$ & 0.955 & 0.999 & 0.956 & 0.957 \\
\hline \multirow{3}{*}{ SA } & $0 / 0$ & 0.845 & 0.999 & 0.962 & 0.998 \\
\hline & $15 / 15$ & 0.878 & 0.998 & 0.958 & 0.996 \\
\hline & $50 / 50$ & 0.940 & 0.999 & 0.964 & 0.982 \\
\hline \multirow{3}{*}{ BSA } & $0 / 0$ & 0.481 & 0.995 & 0.740 & 0.920 \\
\hline & $15 / 15$ & 0.432 & 0.981 & 0.652 & 0.856 \\
\hline & $50 / 50$ & 0.823 & 0.999 & 0.919 & 0.976 \\
\hline \multirow{3}{*}{ Mixture } & $0 / 0$ & 0.609 & 0.999 & 0.883 & 0.990 \\
\hline & $15 / 15$ & 0.615 & 0.999 & 0.748 & 0.857 \\
\hline & $50 / 50$ & 0.947 & 0.999 & 0.955 & 0.962 \\
\hline
\end{tabular}

691 
Table 2 Principal reactions in the Fe(II)/PMS process.

\begin{tabular}{|c|c|c|c|}
\hline No. & Reaction & Rate constant & Reference \\
\hline 1 & $\mathrm{Fe}^{2+}+\mathrm{HSO}_{5}^{-} \rightarrow \mathrm{Fe}^{3+}+\mathrm{SO}_{4}^{--}+\mathrm{OH}^{-}$ & $3.0 \times 10^{4} \mathrm{M}^{-1} \mathrm{~s}^{-1}$ & (Rastogi et al., 2009b) \\
\hline 2 & $\mathrm{SO}_{4}{ }^{--}+\mathrm{OH}^{-} \rightarrow{ }^{\circ} \mathrm{OH}+\mathrm{SO}_{4}{ }^{2-}$ & $(6.5 \pm 1.0) \times 10^{7} \mathrm{M}^{-1} \mathrm{~s}^{-1}$ & (Ji et al., 2014) \\
\hline 3 & ${ }^{\circ} \mathrm{OH}+\mathrm{SO}_{4}^{2-} \rightarrow \mathrm{SO}_{4}^{--}+\mathrm{OH}^{-}$ & $1.18 \times 10^{6} \mathrm{M}^{-1} \mathrm{~s}^{-1}$ & (Khan et al., 2013) \\
\hline 4 & $\mathrm{Fe}^{2+}+\mathrm{SO}_{4}^{--} \rightarrow \mathrm{Fe}^{3+}+\mathrm{SO}_{4}^{2-}$ & $3.0 \times 10^{8} \mathrm{M}^{-1} \mathrm{~s}^{-1}$ & (Rastogi et al., 2009b) \\
\hline 5 & $\mathrm{Fe}^{2+}+{ }^{\circ} \mathrm{OH} \rightarrow \mathrm{Fe}^{3+}+\mathrm{OH}^{-}$ & $4.3 \times 10^{8} \mathrm{M}^{-1} \mathrm{~s}^{-1}$ & (Khan et al., 2013) \\
\hline 6 & $\mathrm{SO}_{4}^{--}+\mathrm{ATZ} \rightarrow$ products & $(2.6-3.5) \times 10^{9} \mathrm{M}^{-1} \mathrm{~s}^{-1}$ & (Yang et al., 2015) \\
\hline 7 & ${ }^{\circ} \mathrm{OH}+\mathrm{ATZ} \rightarrow$ products & $(2.5-3.0) \times 10^{9} \mathrm{M}^{-1} \mathrm{~s}^{-1}$ & (Yang et al., 2015) \\
\hline 8 & $\mathrm{SO}_{4}^{--}+\mathrm{HA} \rightarrow$ products & $6.8 \times 10^{3} \mathrm{~L} \mathrm{mgC}^{-1} \mathrm{~s}^{-1}$ & (Lutze et al., 2015) \\
\hline 9 & $\cdot \mathrm{OH}+\mathrm{HA} \rightarrow$ products & $1.4 \times 10^{4} \mathrm{~L} \mathrm{mgC}^{-1} \mathrm{~s}^{-1}$ & (Lutze et al., 2015) \\
\hline
\end{tabular}

693 Table 3 PMS consumption with time and residual Fe during Fe(II)/PMS

694 pretreatment. Experimental condition: $[\mathrm{HA}]_{0}=10 \mathrm{mg} / \mathrm{L}, \mathrm{pH}=7.0$.

\begin{tabular}{ccccccc}
\hline $\begin{array}{c}{[\mathrm{Fe}(\mathrm{II})]_{0}} \\
(\mu \mathrm{M})\end{array}$ & $\begin{array}{c}{[\mathrm{PMS}]_{0}} \\
(\mu \mathrm{M})\end{array}$ & \multicolumn{6}{c}{ PMS concentration variation with time $(\mu \mathrm{M})$} & $\begin{array}{c}\text { Residual Fe } \\
(\mu \mathrm{M})\end{array}$ \\
\hline 15 & 15 & 1.6 & 1.4 & 1.3 & 1.3 & 2.3 \\
15 & 50 & 36.2 & 34.9 & 34.2 & 34 & 1.1 \\
50 & 15 & 1.0 & $\mathrm{ND}$ & $\mathrm{ND}$ & $\mathrm{ND}$ & 27.2 \\
50 & 50 & 3.5 & 3.1 & 2.8 & 2.8 & 4.8 \\
\hline
\end{tabular}

695

ND, not detected.

696 
698 Fig. 1 Effects of Fe(II)/PMS pretreatment on membrane fouling by HA: (a) Flux

699 decline and (b) Reversibility. Error bars represent standard deviations (n=3).

700 Fig. 2 Effects of Fe(II)/PMS pretreatment on membrane fouling by SA: (a) Flux

701 decline and (b) Reversibility.

702 Fig. 3 Effects of Fe(II)/PMS pretreatment on membrane fouling by BSA: (a) Flux

703 decline and (b) Reversibility.

704 Fig. 4 Effects of Fe(II)/PMS pretreatment on membrane fouling by HA-SA-BSA

705 mixture: (a) Flux decline and (b) Reversibility.

706 Fig. 5 DOC (a) and $\mathrm{UV}_{254}$ (b) levels of the UF feed water with and without 707 treatment with $\mathrm{Fe}(\mathrm{II}) / \mathrm{PMS}$ and $\mathrm{Fe}(\mathrm{III})$ coagulation.

708 Fig. 6 Fluorescence intensity of each component for the UF feed water with and 709 without treatment with Fe(II)/PMS and Fe(III) coagulation.

710 Fig. 7 HPSEC chromatograms of the UF feed water with and without treatment with

711 Fe(II)/PMS and Fe(III) coagulation: (a) HA, (b) HA-SA-BSA mixture.

712 Fig. 8 Removal of ATZ: (a) effect of Fe(II)/PMS and Fe(III) pretreatments on the UF 713 feed and permeate, (b) effect of TBA and methanol on the Fe(II)/PMS process. 714 Conditions: $[\mathrm{ATZ}]_{0}=1 \mu \mathrm{M},[\mathrm{HA}]_{0}=10 \mathrm{mg} / \mathrm{L}, \mathrm{pH}=7.0 \pm 0.1$. 
715 Fig. 1 Effects of Fe(II)/PMS pretreatment on membrane fouling by HA: (a) Flux 716 decline and (b) Reversibility. Error bars represent standard deviations $(n=3)$.
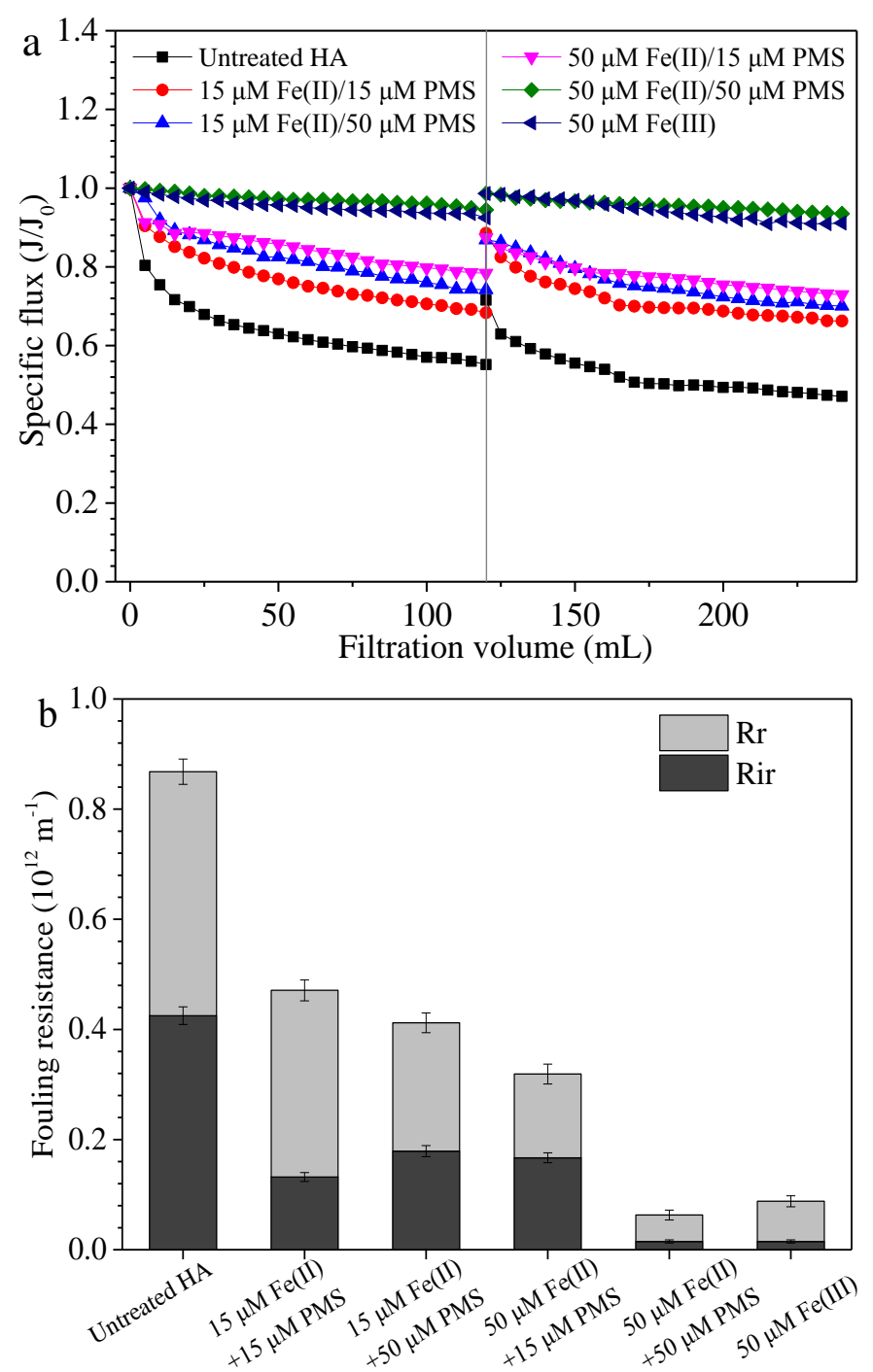
718 Fig. 2 Effects of Fe(II)/PMS pretreatment on membrane fouling by SA: (a) Flux 719 decline and (b) Reversibility.
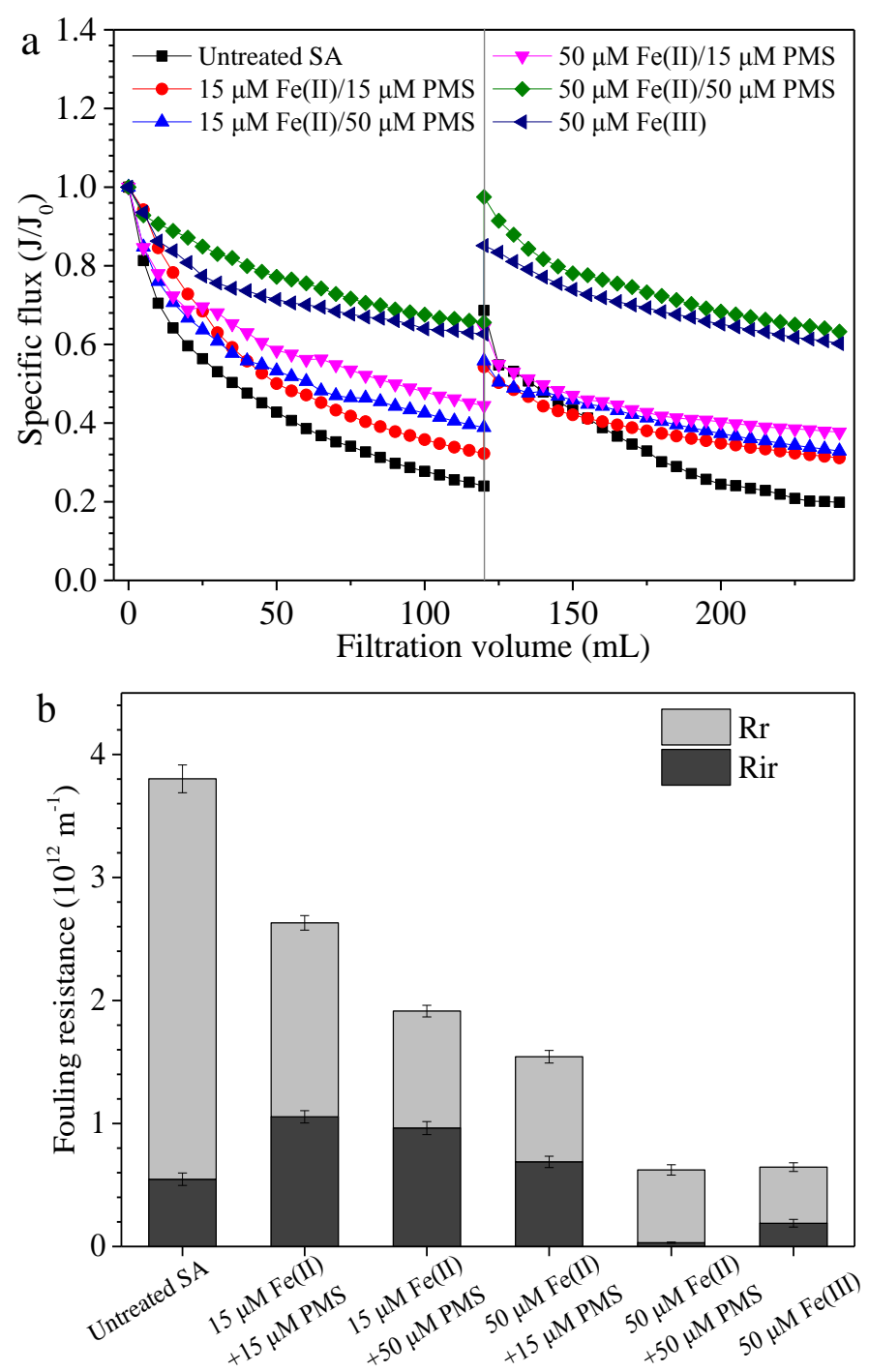
721 Fig. 3 Effects of Fe(II)/PMS pretreatment on membrane fouling by BSA: (a) Flux 722 decline and (b) Reversibility.
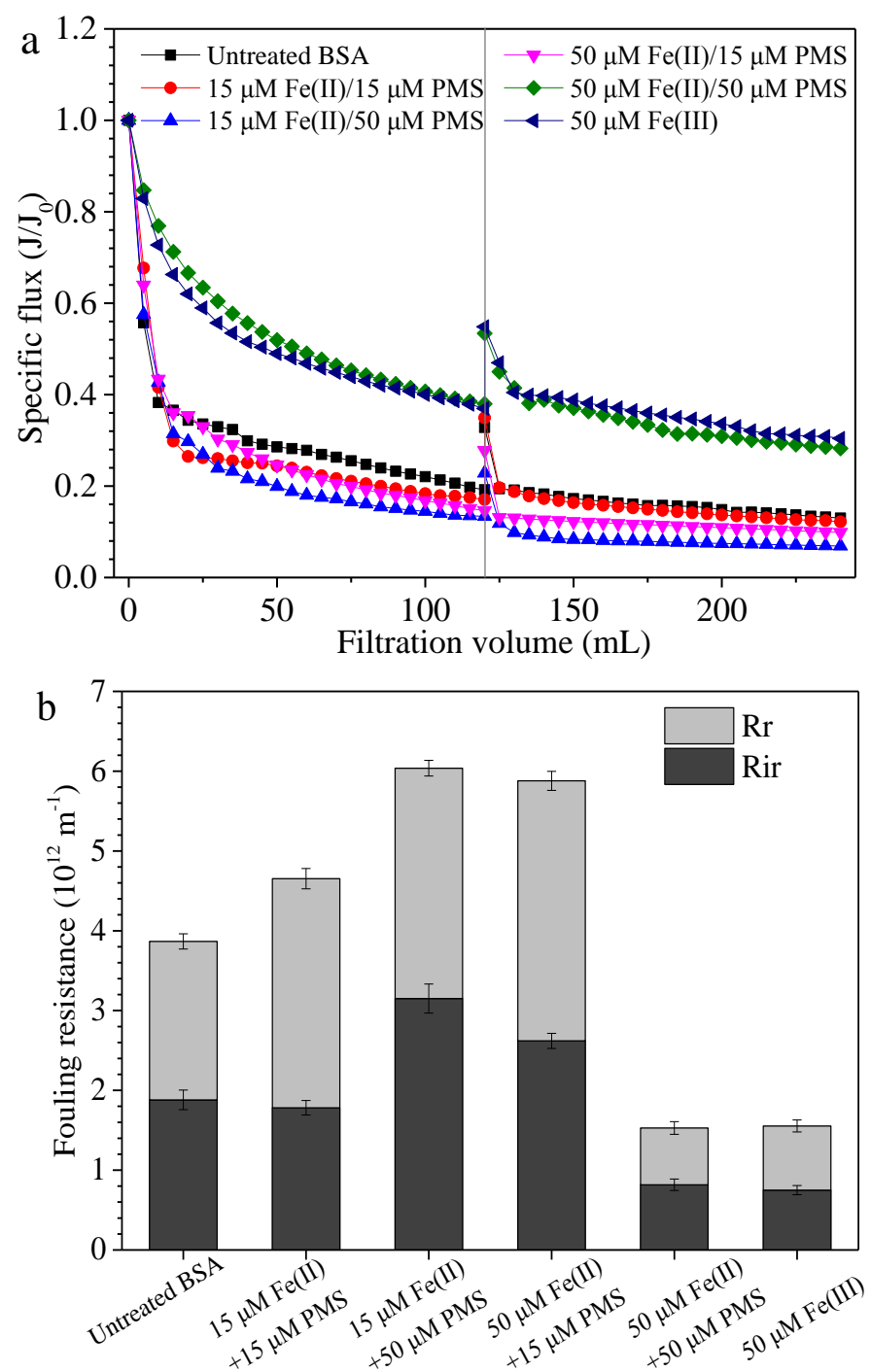
724 Fig. 4 Effects of Fe(II)/PMS pretreatment on membrane fouling by HA-SA-BSA

725 mixture: (a) Flux decline and (b) Reversibility.
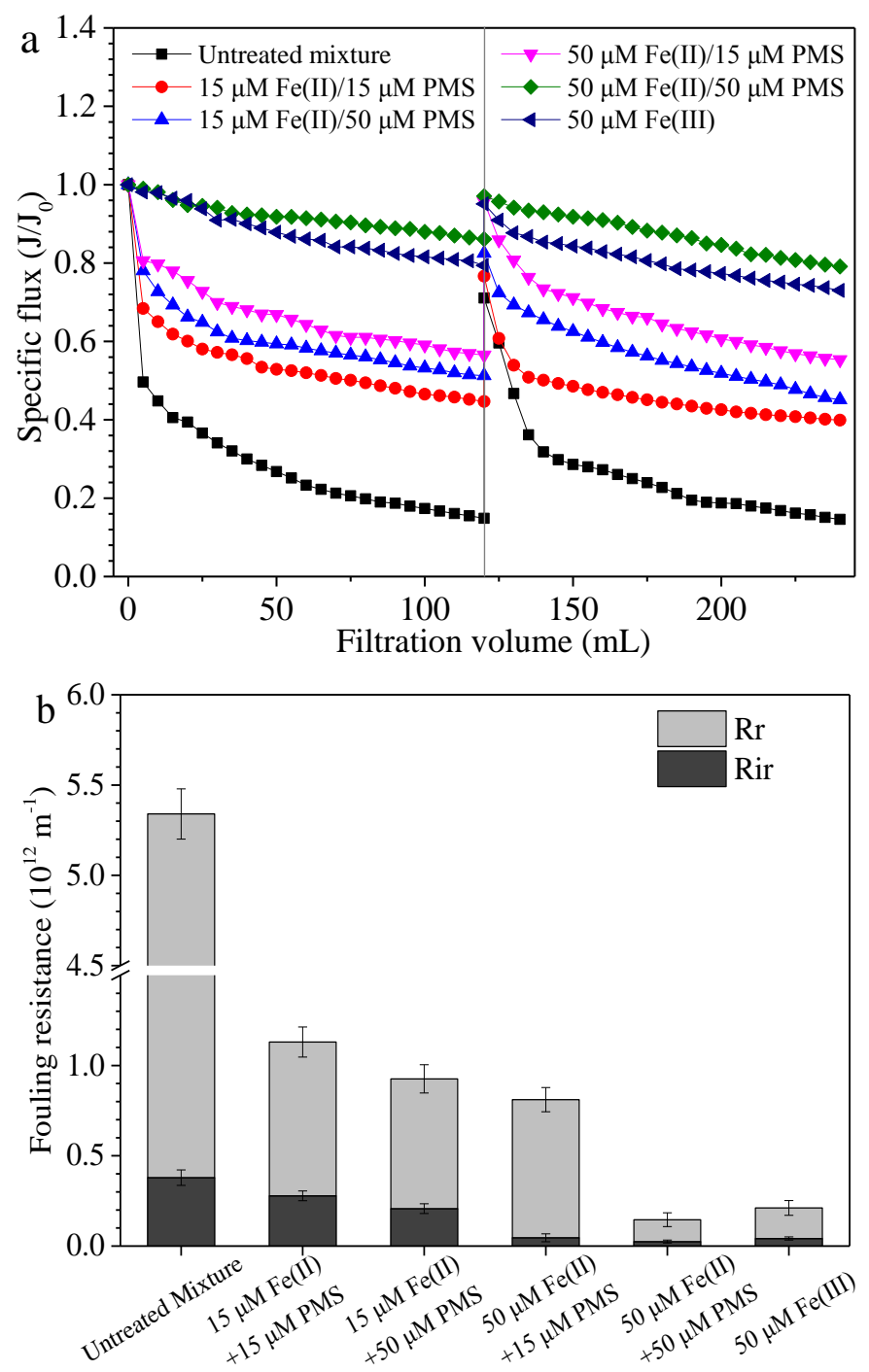
728 treatment with $\mathrm{Fe}(\mathrm{II}) / \mathrm{PMS}$ and $\mathrm{Fe}(\mathrm{III})$ coagulation.
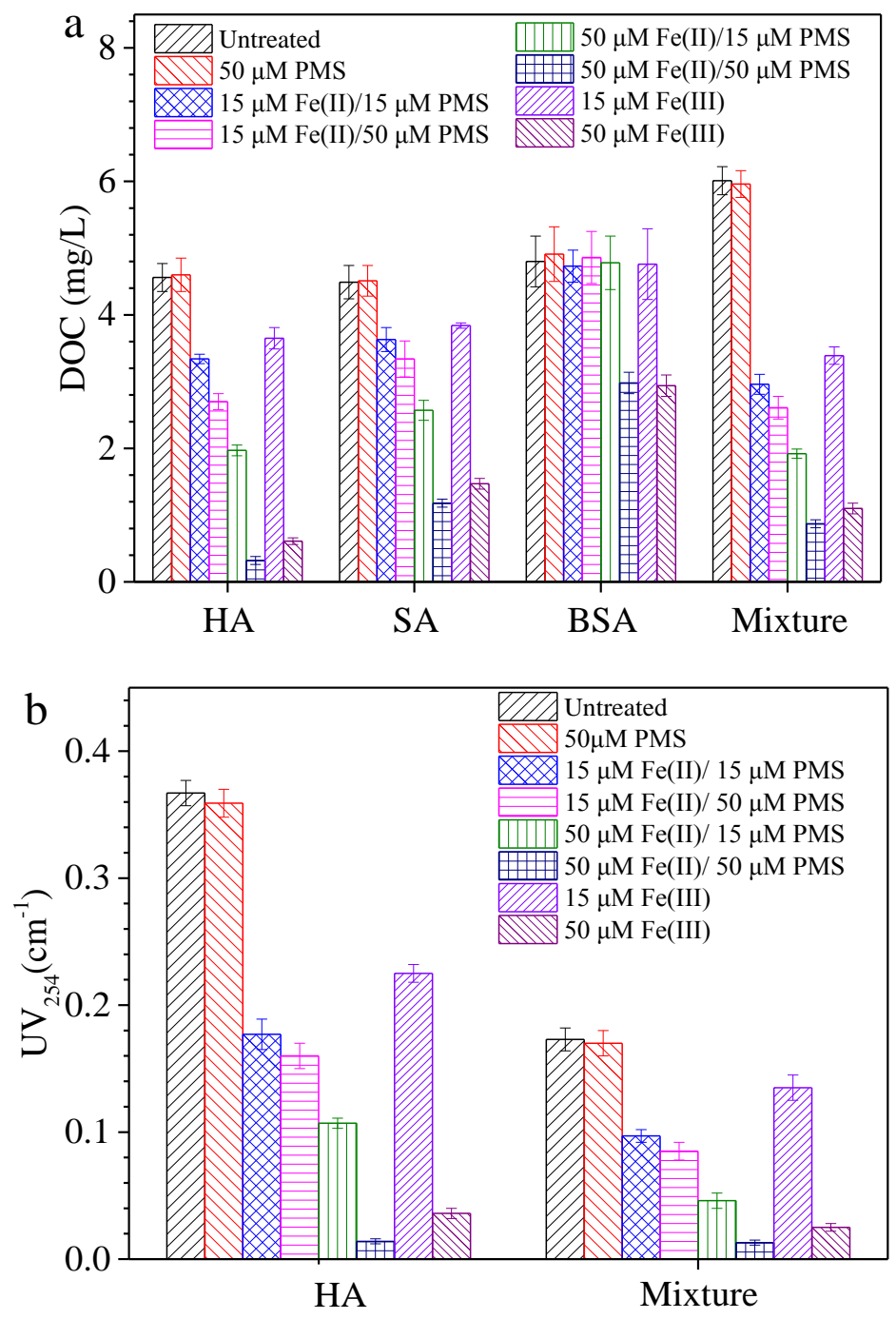

HA 
731 Fig. 6 Fluorescence intensity of each component for the UF feed water with and 732 without treatment with Fe(II)/PMS and Fe(III) coagulation.

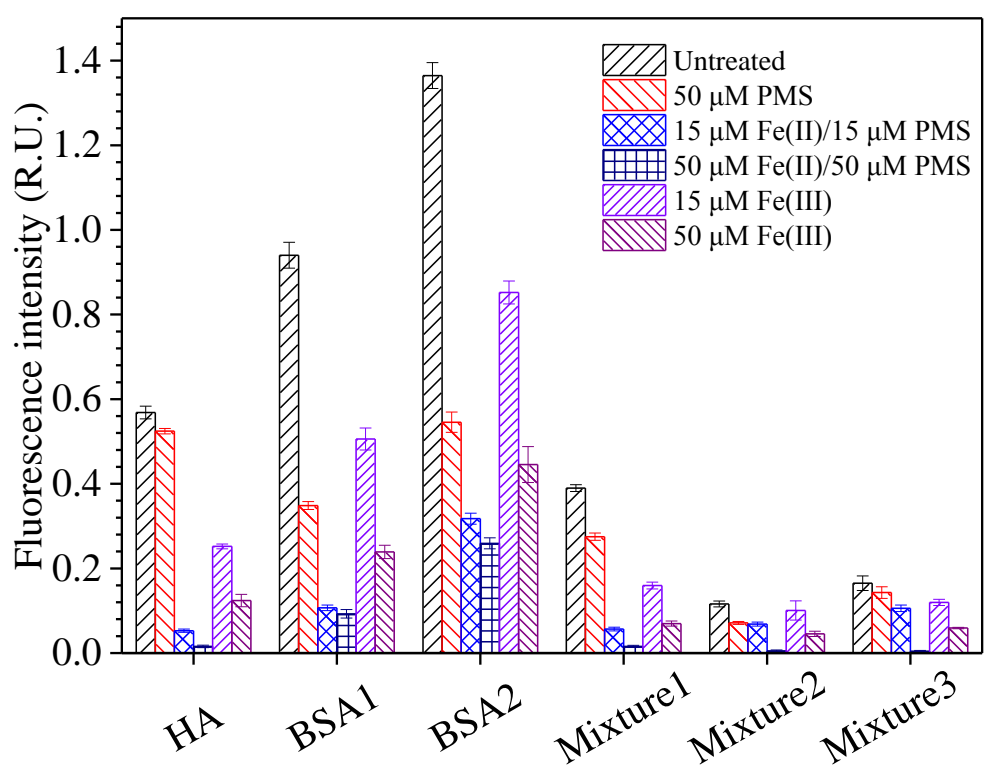


734 Fig. 7 HPSEC chromatograms of the UF feed water with and without treatment with

$735 \mathrm{Fe}(\mathrm{II}) / \mathrm{PMS}$ and Fe(III) coagulation: (a) HA, (b) HA-SA-BSA mixture.
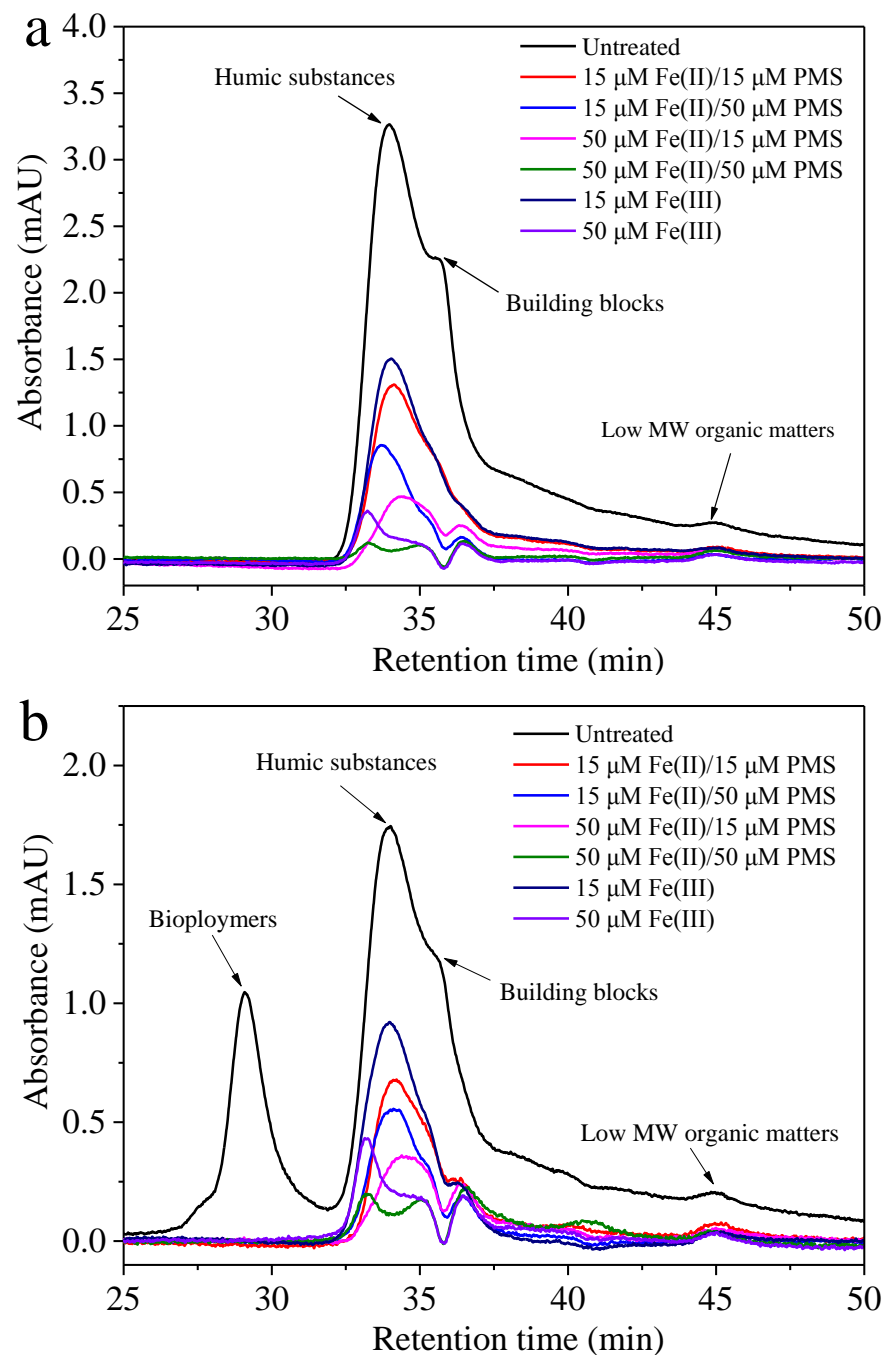
737 Fig. 8 Removal of ATZ: (a) effect of Fe(II)/PMS and Fe(III) pretreatments on the UF 738 feed and permeate, (b) effect of TBA and methanol on the Fe(II)/PMS process.

739 Conditions: $[\mathrm{ATZ}]_{0}=1.0 \mu \mathrm{M},[\mathrm{HA}]_{0}=10.0 \mathrm{mg} / \mathrm{L}, \mathrm{pH}=7.0 \pm 0.1$.
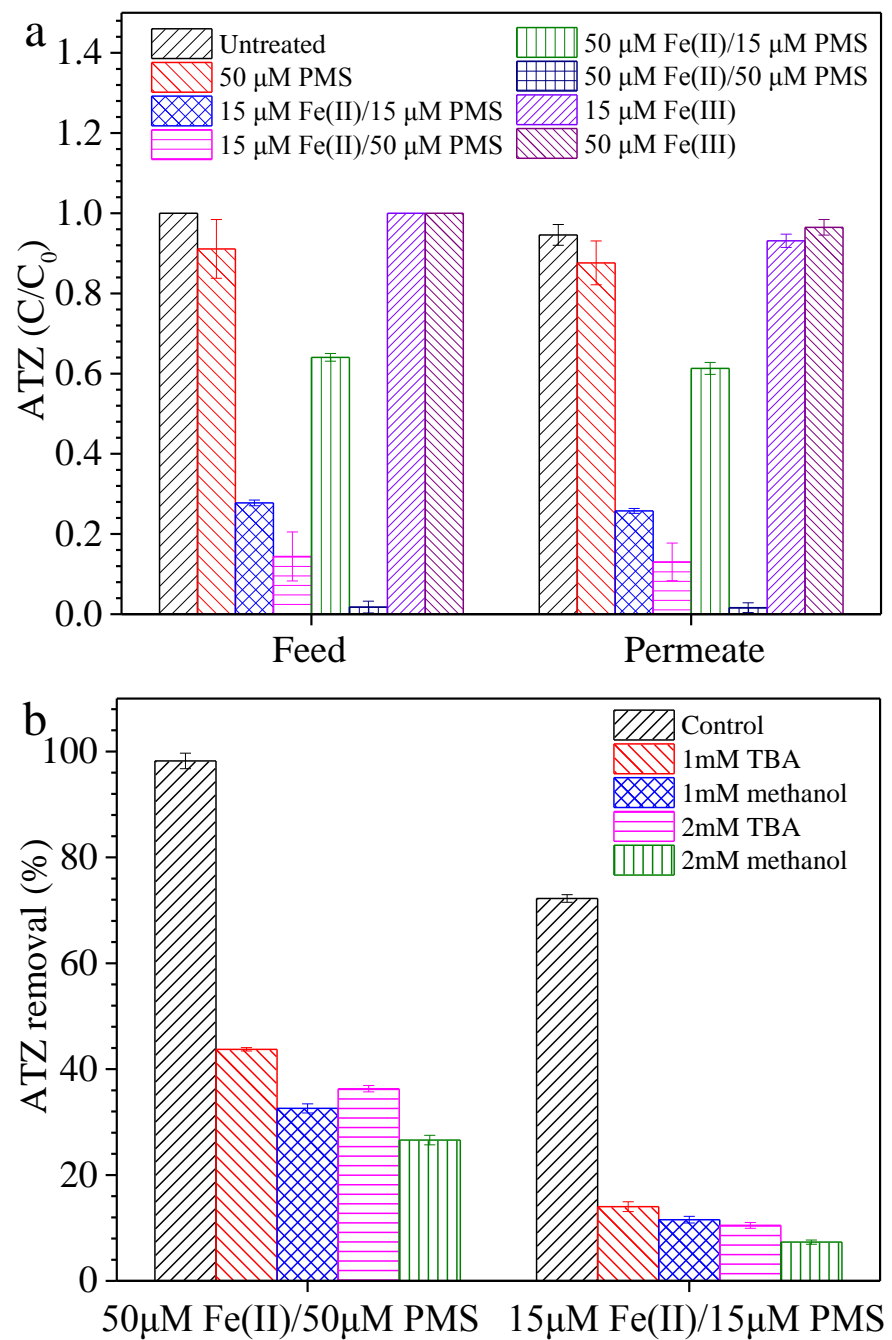
743

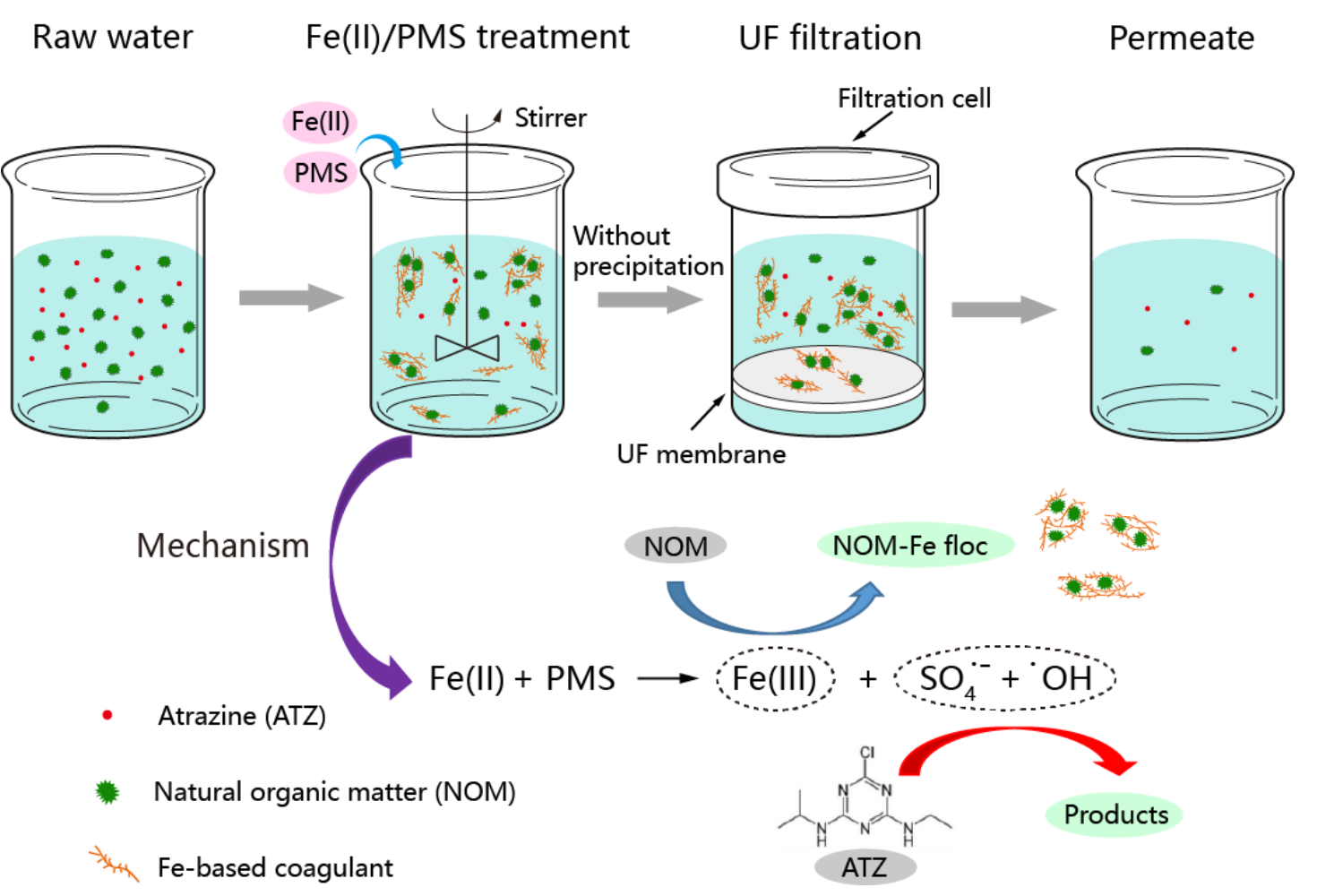

744

745 